\title{
Review on Collaborative Decision Making in Supply Chain: The Relationship between E-Collaboration Technology and Development of Inter-organizational Trust
}

\author{
Nora Azima Noordin ${ }^{1}$, Umit S. Bititci ${ }^{1}$, and Robert Van Der Meer ${ }^{2}$ \\ ${ }^{1}$ Department of Design, Manufacture and Engineering Management \\ \{nora.noordin, u.s.bititci\} astrath.ac.uk \\ ${ }^{2}$ Department of Management Science \\ University of Strathclyde, Glasgow, UK \\ \{robert-van. der.meer\} estrath.ac.uk
}

\begin{abstract}
In successful supply chain collaborations, effective communication and the development of inter-organizational trust are a key factor. The purpose of these literature review paper is to initially review the previous literature on the relationship between the adoption of e-collaboration technology and factors influencing the development of trust in supply chain collaborations. This study is important to answer the questions whether the adoption of e-collaboration technology may help or hinder inter-organizational trust in collaborative decision-making in supply chain area.
\end{abstract}

Keywords: Supply Chain Management, Supply Chain Collaboration, Collaborative Decision-Making, E-Collaboration Technology, Inter-Organizational Trust.

\section{Introduction}

The literature review found that there are key elements to create successful supply chain collaboration; cross-functional activities, process alignment, joint decisionmaking and supply chain metrics (Barratt, 2004). Nowadays, the collaborations have expanded globally. It is important to open and develop clear and broad lines of communication (Frankel et al, 2002), to foster information sharing and to create a shared understanding (Ireland and Bruce, 2000). Rapid changes in information and communication technology (ICT) have eased the way to collaborate. Partners in collaborative companies can communicate and exchange information easily and of course cheaply using advanced technology in ICT such as e-collaboration technology. Evidently, the number of companies working together for a mutual objective is accelerating and has almost doubled in the past ten years. It is also predicted this will further increase in the future (Zineldin and Bredenlow, 2003).

Successful partner relationships involve the existence of several characteristic traits and it is widely acknowledged that trust is one of them (Wehmeyer and Riemer, 2007). 
Trust that will be discussed in this research is 'inter-organizational trust' in the context of collaborative supply chain. Scholars from a number of disciplines have agreed conceptually and empirically that inter-organizational trust, as well as trust in general, plays vital roles in firm behavior and performance. Issues associated with organizational trust have generated deal of broad scholarly interest. There are significant amounts of literature discussing trust in organizational context as well as some other interesting fields such as interpersonal trust and social networks. However, there are lacks of scholarly work on relationship between e-collaboration technology and inter-organizational trust in supply chain area. Thus, the goal of this paper is to investigate and initially review the previous works on the relationship of e-collaboration adoption and factors influencing the development of inter-organizational trust, specifically in the context of collaborative decision-making in supply chain.

The following sections will be organized as follow: Section 2 describes the methodology and process used to carry out the literature review. Section 3 addresses the definition of the terms discussed in this paper based on the previous literature. Section 4 presents the results of this review, we survey the literature on the relationship of e-collaboration adoption and inter-organizational trust in collaborative supply chain, identify and integrate the key themes that emerge from the empirical contribution on the subject. Then, several factors that influence the development of inter-organizational trust are described. Finally section 5 concludes the findings of the paper and directions for future research.

\section{Methodology}

The information used in this study was gathered using a systematic literature review approach as described in Figure 1. The three research questions taken into consideration were as below.

Table 1. Literature Review Process

\begin{tabular}{|l|l|}
\hline $\begin{array}{l}\text { Research } \\
\text { Questions }\end{array}$ & $\begin{array}{l}\text { 1. What are the types of collaborative decisions in supply chain? } \\
\text { What kind of E-Collaboration technology adopted in decision- } \\
\text { making process? }\end{array}$ \\
$\begin{array}{l}\text { 3. What are the factors influencing inter-organizational trust } \\
\text { development? }\end{array}$ \\
\hline $\begin{array}{l}\text { Boundary } \\
\text { Setting }\end{array}$ & $\begin{array}{l}\text { Search engines: Science Direct, ISI Web of Knowledge, Emerald, } \\
\text { SAGE Journal, Elsevier. } \\
\text { Keyword entered: Supply Chain Management, Supply Chain Collabo- } \\
\text { ration, Collaborative Decision-Making, E-Collaboration Technology, } \\
\text { E-Business Technology, Inter-Organizational Trust } \\
\text { Search field: Abstract, Title } \\
\text { Typology: Journal Paper, Conference Paper } \\
\text { Research Methodology: Empirical Research, Literature Review }\end{array}$ \\
\hline
\end{tabular}

The study initially reviews four types of literature; the literature on collaborative supply chain, collaborative decision-making, e-collaboration technology and 
inter-organizational trust. However, not all type of research issues were selected, only papers that made contribution to the research objectives was selected during the review process.

It started with exploring random literature review in order to get the view on earlier and current researches done in the topics until the research gap was found. Then the systematic literature review approach was adopted during the process of selecting relevant literatures. The researcher applied the concept of systematic literature review to identify high quality literature. A systematic literature review involves two processes (Easterby-Smith et al, 2008):

Defining reviews protocols and mapping the field by accessing, retrieving, and judging the quality and relevance of studies in your research areas and reporting the findings to identify where gaps in the current research exist and so indicate where your research might make a useful contribution.

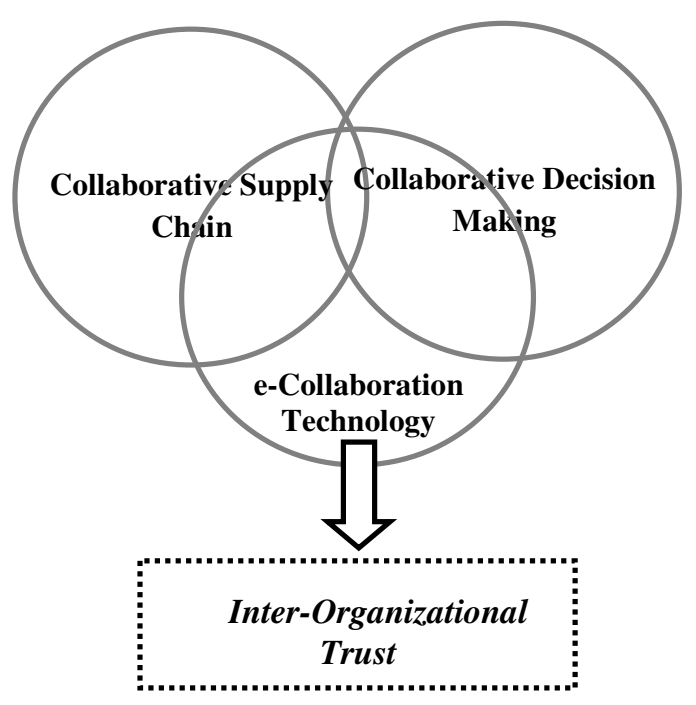

Fig. 1. This figure shows the research gap between three types of research areas. Interorganizational trust is a result from the integration between collaborative processes in supply chain activities that become a research gap for this study.

\section{Definition and Terms}

There are several terms that need to be defined clearly in this paper. The study consists of four types of broad research areas; supply chain collaboration, collaborative decision-making, collaborative technology and inter-organizational trust. Each area has its own definition and meaning. This paper identifies definitions of each area from the previous literatures that contain a number of different definitions to refer to the same object. 


\subsection{What Is Collaboration?}

Collaboration, in the context of supply chain is still relatively embryonic. Collaboration is a very broad and encompassing term and when it is put in the context of the supply chain, it needs yet further clarification (Barratt, 2004). Bititci, 2007, Jordan Jr. and Michel, (2000) defined collaboration literally as 'working together'. The term is often used when individuals or organizations work together towards some common aim. Huxam (1996) suggested collaboration as a positive form of working in association with others for some form of mutual benefits. Cropper (1996) defined it as a distinctive mode of organizing with a positive and purposive relationship between organizations that retain autonomy, integrity and distinct identity, but at the same time, the possibility to withdraw from the relationship is exist.

All of the above definitions are similar and complementary each other. For the purpose of this review, authors attempt to combine them into single comprehensive definition that cover all of dimensions on existing literature as follow:

"Collaboration is a number of autonomous organizations in the supply chain that are actively working together towards common objectives, and is characterized by sharing information, knowledge and risk for mutual benefits. Collaborative organizations make decisions together and it is mutual goal setting that goes far beyond a written contract."

\subsection{Collaborative Decision-Making}

Essentially, collaborative decision-making is a process of doing decisions together and achieving same agreement from collaborated parties. It involves process of identifying and choosing alternative courses of action in a manner appropriate to the demand of the situations. In management decisions, terms that most often used suggested by Ofstad (1961). Management decision has been defined in many ways. As suggested by Ofstad: “...to say that a (manager) has made a decision may mean: (1) that he (or she) has started a series of (actions) in favor of something, or it may mean (2) that he (or she) has made up his (or her) mind to do a certain (thing)... But perhaps the most common use of the term is: "to make a decision" means (3) to make a judgment regarding what one ought to do in a certain situation after having deliberated on some alternative courses of action (Ofstad, 1961).

In this research, the authors apply decision's definition suggested by Harrison (2000); a decision is defined as:

"A moment in an ongoing process of evaluating alternatives for meeting an objective, at which expectations about a particular course of action impel the decision maker to select that course of action most likely to result in attaining the objective".

\subsection{E-Collaboration Technology}

Electronic collaboration technology (e-Collaboration) is operationally defined as collaboration using electronic technologies among different individuals to accomplish a common task (Kock and D’Arcy, 2002, 2001). McDonell (2001) considers e-collaboration 
as internet-based collaborations, which integrates people and processes giving flexibility to supply and service chain. There are other streams in defining e-collaboration as virtual teaming of structured communication activities by using electronic tools. IBM defined ecollaboration as anything that allows people to collaborate or work together more easily using electronic tools.

In this paper, e-collaboration technology in the context of supply chain is referred to the Internet-based communication platforms used by collaborative organizations to communicate and sharing information and a platform that can be used to assist decision-making process during online meeting. The authors agree with e-collaboration definition in the context of supply chain suggested by Johnson and Whang (2002):

"E-collaboration is business-to-business interactions facilitated by the Internet. These interactions go beyond simple buy/sell transactions and may be better described as relationships. These include such activities as information sharing and integration, decision sharing, process sharing and resources sharing”.

\subsection{Definition of Trust and Inter-organizational Trust}

For the last two decades researchers from various disciplines have interpreted trust in different ways and given different dimensions by focusing on specific aspect of trust. Studies from Laeequddin et al. (2010) identify trust in different context and in each context trust can be bestowed upon a person, place, event or object (Giffin, 1967), between individuals (George and Swap, 1982; Mayer et al., 1995), organizations (Gulati, 1995), individuals and organizations (Zaheer et al., 1998), partner's competence (Barber, 1983), process, characteristics and institutions (Zucker, 1986), system (Giddens, 1990), calculations (Anderson and Narus, 1990), economics (Larson, 1992), intentional relations (Nooteboom et al., 1997) and between a user and an IT system (Lippert, 2001), technology (Jones et al., 2000), or financial services (Wang, 2008). Trust may function as glues $\mathrm{n}$ a relationship (Jarillo, 1988) and trust may function as a lubricant (Arrow, 1974).

Different concepts of trust have been provided by various studies. Basically, trust relations involve participation of at least two parties: the trustor, the party who places him or herself in a vulnerable situation under uncertainty; and the trustee, the party on whom the trust is placed, who has the opportunity to take advantage of the trustor's vulnerability (Laeequddin et al., 2010). Most common used definition of trust is as suggested by some researchers such as by Mayer et al. (1995). He defined trust as "the willingness of a party based on the expectations that the other party will perform a particular action important to the trustor, irrespective of the ability to monitor or control the party". Kim et al. (2009) defined trust as a complex and multifaceted construct.

This study focuses on inter-organizational trust concept. The definition of interorganizational trust that agreed to be used in this research is as suggested by Zaheer, McEvily and Perrone (1998).

"Inter-organizational trust is the extent to which members of one organization hold a collective trust orientation toward another organization”. 


\section{$4 \quad$ Analysis}

\subsection{Decision-Making Concept}

A decision is choice out of several alternatives or options made by the decision maker to achieve some objectives in a given situation. Business decisions are those, which are made in the process of conducting business to achieve its objective and a given environment. Managerial decision-making is a control point for every managerial activity may be planning, staffing, directing, organizing, controlling and communicating. Decision-making is the art of reasoned and judicious choice of many alternatives. Once decision is taken, it implies commitment of resources.

The business managers have to take variety of decisions, some are routine and others are long-term implementation decisions. The managerial decisions are grouped as strategic, tactical and operational decision. Strategic decisions are known as major decision influence whole or major part of the organization. Such decision contributes directly to the achievement of common goals of the organizations, have long-range effect upon the organization. These types of decision are basically based on partial knowledge of the environment factors which are uncertain and dynamic, therefore such decision are taken at the higher level of management. Tactical decision relate to the implementation of strategic decisions, directed towards developing divisional plans, structuring workflows and establishing distribution channels. These decisions are taken at the middle level of management. While operational decision relate to daily operations of the enterprise having a short-term horizon and are always repeated. These decisions are based on facts regarding the events and do not require much business judgments. Operational decisions are taken at lower level of management.

\subsection{Types of Collaborative Decisions in Supply Chain}

The development of an integrated supply chains means the management should take a look of material flow from three perspectives. As suggested by Stevens (1993) the management have to consider three level of management that are strategic, tactical and operational level where each levels have its own task, the use of facilities, people, finance and systems must be coordinated and harmonized as a whole. The focus at strategic level should be to develop are (Stevens, 1993):

- Objectives and policies for the supply chain. These should be expressed in terms of what supply chain has to do well to support the needs of the business for example be responsive to change, operate at lowest cost, ensure a high level of product availability;

- The shape of the supply chain in terms of key facilities and their locations;

- The company's competitive package, planned by product and market availability, service level, lead time, technical support and after-sales support;

- An outline organizational structure able to bridge functional barriers and operate an integrated supply chain effectively.

From the tactical perspective, the management should focus on the means by which the strategic objectives can be realized. It involves translating the strategic objectives 
into goals for each function, enabling the functions to provide complementary balance as parts of the supply chain. The functional goals provide the focus for achieving the balance, and inventory, capacity and service are the levers by which balance is achieved. The operational perspective should be concerned with the efficient operation of the supply chain. It focuses on the detailed systems and procedures, and ensures that appropriate controls and performance measures are in place. Typically, a company should measure the performance of the supply chain in terms of five areas as suggested by (Stevens, 1993):

- Inventory investment;

- Service level;

- Throughput efficiency;

- Supplier performance;

- Cost.

Using literature review, this section describes types of collaborative decisions involved in supply chain process. These decisions are made in various levels of supply chain management; strategic, tactical and operational level. Each level has its own activities and processes that need decision-making integration between collaborated supply chain organizations. Generally, Table 2 describes type of processes and decisions involve in supply chain activity in each level.

Table 2. Types of Decisions in Supply Chain Process

\begin{tabular}{|c|c|}
\hline \multicolumn{2}{|l|}{ Strategic Level } \\
\hline Muckstad et al. (2001) & $\begin{array}{l}\text { Strategic decisions typically deal with market entry and } \\
\text { mobilizing resources needed to meet market requirements } \\
\text { over time. }\end{array}$ \\
\hline Van Goor et al. (1996) & $\begin{array}{l}\text { Strategic logistics decisions concern major capital com- } \\
\text { mitments and long time horizon, including the location } \\
\text { choices between a distribution networks or more basic } \\
\text { make or buy decisions }\end{array}$ \\
\hline \multicolumn{2}{|l|}{ Tactical Level } \\
\hline Huin et al. (2002) & $\begin{array}{l}\text { Medium level decisions are made, such as weekly de- } \\
\text { mand forecasting, distribution and transportation plan- } \\
\text { ning, and materials requirement planning. }\end{array}$ \\
\hline \multicolumn{2}{|l|}{ Operational Level } \\
\hline Huin et al. (2002) & $\begin{array}{l}\text { Operational level is concerned with the very short-term } \\
\text { decisions made from day-to-day. }\end{array}$ \\
\hline
\end{tabular}


Table 2. (continued)

Van Goor et al. (1996)

Operational logistics decision-making relates to day-to-day operations and usually involves low capital investment. Examples include the order control policy (frequency, replenishment time, back order procedures), order picking (order picking strategy procedure, warehouse routing) and route planning (scheduling, assignment of vehicles).

The Supply Chain Planning Matrix by Fleischmann et al. (2002) classifies the planning tasks in two dimensions "planning horizon" and "supply chain process". Figure 2 below shows typical supply chain tasks but with various contents in the particular supply chain levels.

However, some scholars agreed that it remains disputable at what level of decisionmaking a particular decision should be allocated (Becker et al., 2004). The border between the tactical and operational levels is vague (Laubacher et al., 1997), since the fulfillment of actual orders at operational level. The exact position of each decision-making element in the hierarchy therefore remains a question of relativity (Becker et al, 2004).

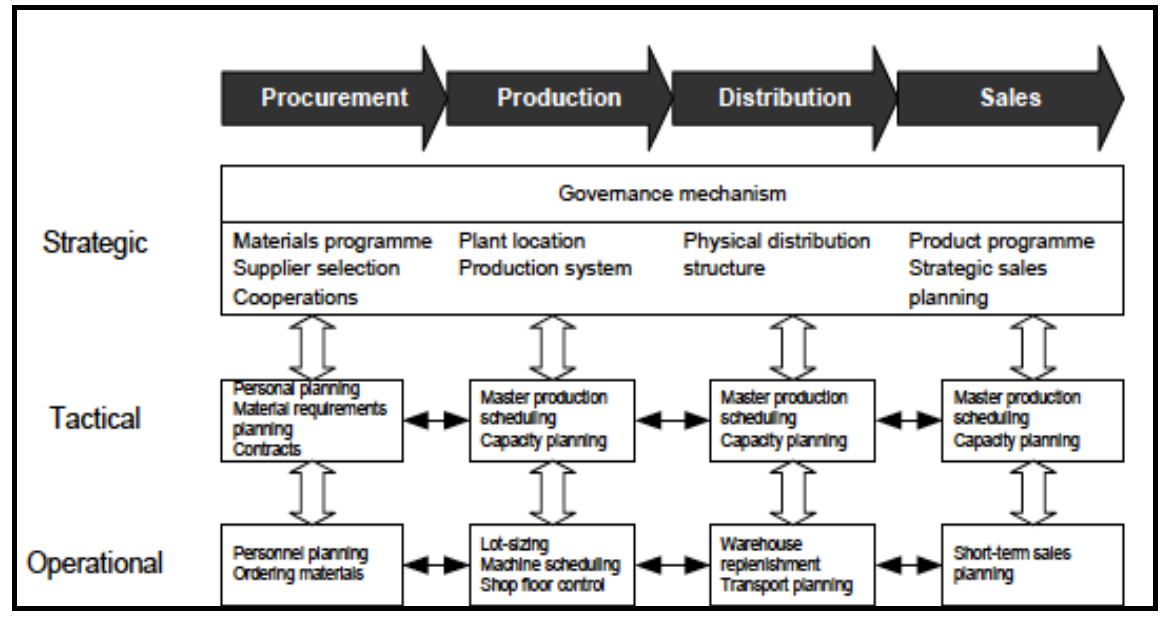

Fig. 2. The Supply Chain Planning Matrix (Rohde et al., 2000; in: Fleischmann et al., 2002; adapted)

\subsection{E-Collaboration Technology Adopted in Decision-Making Process}

Rapid changes in technology gives impact to the style of managing supply chain processes. Collaborations improve supply chain processes by increasing the intensity and scope of co-operative behavior between two or more independent decisionmaking units. Today, collaborative decision-making processes are supported by 
advanced ICT. It is argued that the value and importance of collaboration has changed, as we migrate from traditional supply chain management (SCM) approach to the e-SCM perspective (Williams, 2002). The evolution of supply chain collaboration technology can be seen from 1990's, from EDI to Web service enable. One of the most commonly implemented information technologies that aims to integrate the supply chain processes is Electronic Data Interchange (EDI). However, with the emergence of the Internet, EDI is slowly being replaced by other e-business standards. The main reasons why EDI implementation was seen as a challenge includes the availability of different standards in EDI, not being able to provide real time data transfer and the high implementation cost (Chong and Ooi, 2008). The 1990s saw organizations moving towards implementing business-to-business (B2B) technologies which allow them to integrate their supply chain processes better (Chou et al., 2004). However, researchers such as Chou et al. (2004), Chong et al. (2009) stated that from the year 2000 onwards, organizations have started to move towards using ecollaboration or collaborative commerce tools in their supply chain. E-collaboration tools do not focus on monetary transactions in B2B and instead cover the exchanges of information and ideas between the trading organizations and within organizations and allows them to collaboratively design, develop, build and manage products through their life cycle.

Figure 3 shows timeline of the evolution in supply chain collaboration from 1990 to 2005 (Pramatari, 2007) in retail and enabling technologies and this paper extends the evolution from 2005 to 2011 in Figure 4.

\begin{tabular}{|c|c|c|c|c|c|}
\hline $\begin{array}{l}\text { Evolution of } \\
\text { supply-chain } \\
\text { collaboration } \\
\text { practices }\end{array}$ & CRP/VMI & $\begin{array}{l}\text { Category } \\
\text { Management }\end{array}$ & CPFR & $\begin{array}{l}\text { tore-level } \\
\text { PFR }\end{array}$ & $\begin{array}{l}\text { RFID-enabled } \\
\text { collaboration }\end{array}$ \\
\hline \multirow{2}{*}{$\begin{array}{l}\text { Technological } \\
\text { evolution }\end{array}$} & \multirow[t]{2}{*}{ Classical EDI } & XML & $\begin{array}{l}\text { Web-based } \\
\text { interaction }\end{array}$ & & EPC Network \\
\hline & & Internet EDI & GDSN & $\begin{array}{l}\text { RFID- } \\
\text { EPC Gen1 }\end{array}$ & $\begin{array}{l}\text { RFID- } \\
\text { EPC Gen2 }\end{array}$ \\
\hline & 1990 & 1995 & 2000 & & 2005 \\
\hline
\end{tabular}

Fig. 3. Evolution of supply chain collaboration practices in retail and enabling technologies from 1990 to 2005 (Pramatari, 2007)

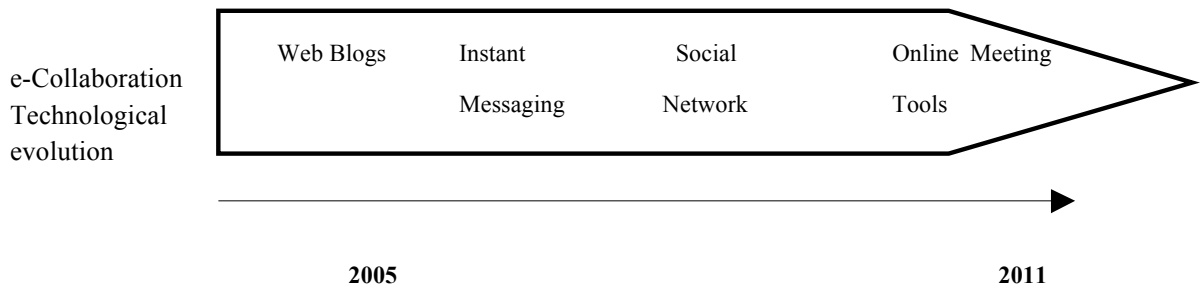

Fig. 4. Evolution of e-collaboration technology to facilitate decision-making in supply chain collaboration 
T. McLaren et al. (2002) further clarified e-collaboration systems into three major types:

(1) Message-based systems that transmit information to partner applications using technologies such as fax, e-mail, EDI, or eXtensible Markup Language (XML) messages;

(2) Electronic procurement hubs, portals, or marketplaces that facilitate purchasing of goods or services from electronic catalogues, tenders, or auctions;

(3) Shared collaborative SCM systems that include collaborative planning, forecasting and replenishment capabilities in addition to electronic procurement functionality.

Rapid development in information communication technology has change the way people communicate. From 2007 until now, the boundary of e-collaboration extents it's capability to the new types of collaborative technology. Social networking and online meeting tools have been widely used by inter- and intra- organizations to facilitate decision-making processes. Of course they can reduce the process cost and time consumption. Besides that, it gives advantage to the organization to leverage the supply chain management network and transform existing business processes especially in the context of decision-making.

The synthesis of the literature leads to the development of evolution in ecollaboration (Figure 3 and 4). E-collaboration evolves from intra- to interorganizational collaboration, from vertical to horizontal collaboration and from operational to strategic level of collaboration.

\subsection{Factors Influencing Inter-organizational Trust Development}

The adoption of e-collaboration technology as medium of communication and decision-making facilitation between collaborated parties arise trusting issues. Trust is a critical factor fostering commitment among supply chain partners. The presence of trust improves measurably the chance of successful supply chain performance (G.Kwon, 2004). Trust plays an important role in the adoption of e-collaboration tools as collaboration involves transparency and sharing of information among the supply chain members. When business partners want to adopt e-collaboration tools in their supply chain collaboration, an organization that trusts its partners is more likely to reach consensus in terms of achievable benefits by e-collaboration tools (Shang et al., 2005). In the case of e-collaboration adoption by inter-organizations, the trust is the firms' willingness to trust their supply chain partners in sharing important supply chain information, for example product design and research and development. Other scholars identifying trust as a significant factor in determining the adoption of interorganizational systems include Ratnasingam (2001), Dubelaar et al. (2005), Barratt (2004), Ngai et al. (2008) and Hart and Saunders (1997).

From sociologist point of view, the role of the past in the creation of trust show that the history of previous interaction between organizations; including familiarity as well as relationship history leads to increased trust (Gulati, 1995). Although previous history clearly does not equate exactly to prospects for extended future collaboration, the question of how past ties and history serve as a signal of the "shadow of the future", and the associated trust or cooperation emanating from it, appears to be an unresolved issues (Zaheer and Harris, 2006). McEvily et al., 2003 suggest that vulneability is an important 
aspect of trust creation. If vulnerability leads to trustworthiness, this may have indirect implications for organizational performance, because trustworthiness and performance have been shown to be linked (Dyer and Chu, 2003).

This study also indicates several other factors that influence inter-organizational trust development and the willingness of using e-collaboration technology as medium of communication as in Table 3 .

Table 3. Factors influencing inter-organizational trust

\begin{tabular}{|l|l|}
\hline \multicolumn{1}{|c|}{ Authors } & \multicolumn{1}{c|}{ Factors influencing trust } \\
\hline $\begin{array}{l}\text { Fukuyama (1995), Husted (1994), } \\
\text { Lane (1997), Lane and Bachmann } \\
\text { (1996), }\end{array}$ & Location and national culture. \\
\hline Dyer and Chu (2000) & $\begin{array}{l}\text { National setting, length of time since the } \\
\text { first interaction. }\end{array}$ \\
\hline $\begin{array}{l}\text { Sako (1998), Dyer and Chu (2003), } \\
\text { Gulati (1995) and Singh (1998) }\end{array}$ & Regional and culture differences \\
\hline $\begin{array}{l}\text { Kramer (1999), Wicks and Berman } \\
(2004)\end{array}$ & $\begin{array}{l}\text { Social, institutional and psychological } \\
\text { norms }\end{array}$ \\
\hline Giddens (1984), Coleman (1990) & Coordination roles, role of third parties \\
\hline Meyerson et al (1996) & Inter-personal trust \\
\hline
\end{tabular}

The argumentation in this section has shown that different aspect has justified the factors influencing inter-organizational trust. Some scholars agreed that the differences in culture and nationality have given impact in the development of trust. Norms and they way of thinking as well as capabilities in technology literacy influence the interorganizational trust.

\subsection{Collaborative Trust}

From a research done by Fawcett et al. (2012), there are four stage of developing trust in supply chain. Stage 1 consists of limited trust, Stage 2 transactional trust, Stage 3 relational trust and Stage 4 collaborative trust. Relationships that reach Stage 4 entail a common belief leading parties to view supply chain partners' capacity and capabilities as an extension of their own business. When this occurs, companies share resources willingly to help partners improve their own processes and competitive positioning. This increased relationship commitment as not based on altruism but it arises out of a philosophy that competitive success depends on the strength of the supply chain team. 


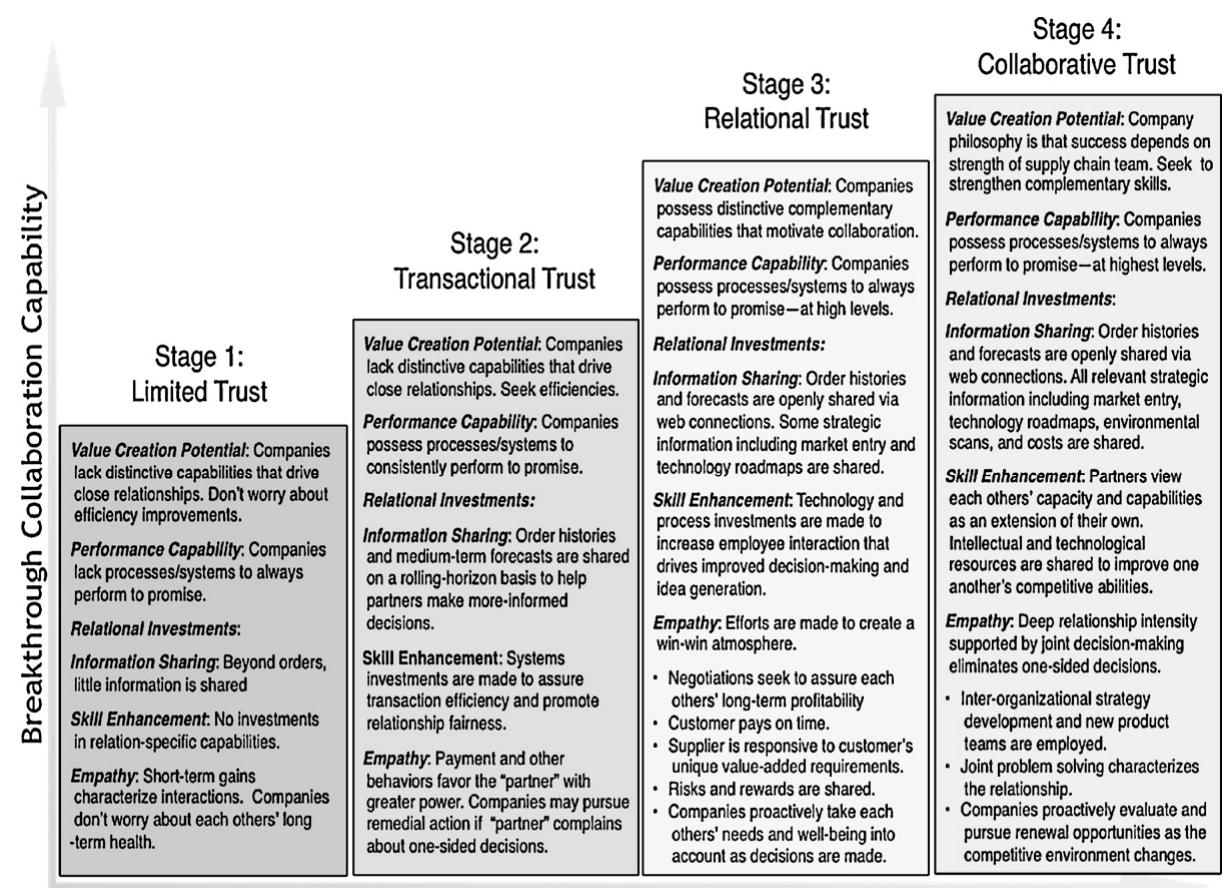

Time, Experience, \& Relationship Intensity

Fig. 5. Trust maturity framework (S.E. Fawcett et al. 2012)

\section{$5 \quad$ Conclusions and Future Research}

Using a literature review, this study described the relationship of e-collaboration adoption and factors influencing the development of inter-organizational trust, specifically in the context of collaboration decision-making in supply chain. Our analysis showed that types of decisions involve in supply chain are varies depending on the level of supply chain management. These decisions are made in various levels of supply chain management; strategic, tactical and operational level. Each level has its own activities and processes that need decision-making integration between collaborated supply chain organizations. The evolution in information communication technology has changed the way people communicate. This scenario able to assists collaborative companies to use the e-collaboration technology as a medium of communication and to make decision-making process more efficient. It gives advantage to the organization to leverage the supply chain management network and transform existing business processes especially in the context of decision-making. Trust plays an important role in the adoption of e-collaboration tools as collaboration involves transparency and sharing of information among the supply chain members. This study revealed several factors that influencing trust development between collaborated companies such as the company's past collaboration record, roles of inter-personal trust between people in the organization, culture differences and national setting. 
There are significant amounts of literature discussing trust in organizational context as well as some other interesting fields such as interpersonal trust and social networks. However, there are lacks of scholarly work on relationship of e-collaboration technology and inter-organizational trust in supply chain area. Little empirical research has been carried out to assess the e-collaboration technology and it effectiveness in the context of decision-making process. This has been given opportunity for future research and to explore issues that are not studied in the literature.

\section{References}

1. Alain, Y.L.C., Keng-Boon, O., Amrik, S.: The Relationship Between Supply Chain Factors and Adoption of e-Collaboration Tools: An Empirical Examination. International Journal Production Economics (2009)

2. Anderson, J.C., Narus, J.A.: A Model of Distributor Firm and Manufacturing Firm Working Partnerships. Journal of Marketing (54), 42-58 (1990)

3. Arrow, K.: The Limits of Organization. W.W. Norton and Co., New York (1974)

4. Barber, B.: The Logic and Limits or Trust. Rutgers University Press, New Brunswick (1983)

5. Barratt, M.A.: Understanding the Meaning of Collaboration in Supply Chain. Supply Chain Management: An International Journal 9(1), 30-42 (2004)

6. Becker, J.F.F., Verduijn, T.M., Kumar, K.: Supply Chain Collaboration Across Strategic, Tactical and Operational Planning (2004),

http: / / www.klict.org/docs / PPhr175.pdf

7. Bill, W., Irma Becerra, F.: Managing Trust and Commitment in Collaborative Supply Chain Relationships. Communication of the ACM 44(6), 67-73 (2001)

8. Bititci, U., Turner, T., Mackay, D., Keaney, D., Parung, J., Walters, D.: Managing Synergy in Collaborative Enterprises. Production, Planning and Control 18(6), 454-465 (2007)

9. Coleman, J.S.: Foundations of Social Theory. Belknap, Cambridge (1990)

10. Chong, A.Y.L., Ooi, K.B.: Adoption of Interorganizational System Standards in Supply Chains: An Empirical Analysis of RosettaNet Standards. Industrial Management \& Data Systems 108(4), 529-547 (2008)

11. Chou, D.C., Tan, X., Yen, D.C.: Web Technology and Supply Chain Management. Information Management \& Computer Security 12(4), 338-349 (2004)

12. Cropper, S.: Collaborative Working and the Issue Sustainablity. In: Huxam, C. (ed.) Creating Collaboratice Advantage. SAGE Publications Ltd., London (1996)

13. Dubelaar, C., Sohal, A.S., Savic, V.: Benefits, impediments and Critical Success Factors in B2C e-Business Adoption. Technovation 25(11), 1251-1252 (2005)

14. Dyer, J.H., Chu, W.: The Determinants of Trust in Supplier-Automaker Relationships in the U.S, Japan and Korea. Journal of International Business Studies 31(2), 259-285 (2000)

15. Dyer, J.H., Chu, W.: The Role of Trustworthiness in Reducing Transaction Costs and Improving Performance: Empirical Evidence From the U.S, Japan and Korea. Organization Science 14(1), 57-68 (2003)

16. Easterby-Smith, M., Thorpe, R., Jackson, P., Lowe, A.: Management Research, 3rd edn. Sage, London (2008)

17. Fukuyama, F.: Trust: The Social Virtues and The Creation of Prosperity. Free Press, New York (1995)

18. Frankel, R., Goldsby, T.J., Whipple, J.M.: Grocery Industry Collaboration in The Wake of ECR. International Journal of Logistics Management 13(1), 57-72 (2002) 
19. Fleischmann, B., Meyr, H., Wagner, M.: Advanced Planning. In: Stadtler, H., Kilger, C. (eds.) Supply Chain Management and Advanced Planning: Concept, Model, Software and Case Study, 2nd edn., ch. 4, pp. 71-96. Springer (2002)

20. George, J.C., Swap, W.C.: Measurement of Specific Interpersonal Trust: Construction and Validation of a Scale to Access Trust in a Specific Other. Journal of Personality and Social Psychology 43(6), 1306-1317 (1982)

21. Stevens, G.C.: Successful Supply-Chain Management. Management Decision 28(8) (1993)

22. Giddens, A.: The Constitution of Society. Polity Press, Cambridge (1984)

23. Giddens, A.: The Consequences of Modernity. Polity Press, Cambridge (1990)

24. Gulati, R., Singh, H.: The Architecture of Cooperation: Managing Coordination Costs and Appropriation Concerns in Strategic Alliances. Administrative Science Quarterly 43(4), 781-814 (1998)

25. Hart, P., Saunders, C.: Power and Trust - Critical Factors in the Adoption and Use of Electronic Data Interchange. Organization Science 8(1), 23-42 (1997)

26. Harrison, E.F.: A Process Perspective on Strategic Decision Making. Management Decision 34(1), 46-53 (2000)

27. Husted, B.W.: Transaction Costs, Norms and Social Network: A Preliminary Study of Cooperation in Industrial Buyer-Seller Relationships in The U.S and Mexico. Business and Society 33(1), 30-57 (1994)

28. Huin, S.F., Luong, L.H.S., Abhary, K.: Internal Supply Chain Planning Determinants in Small and Medium-Sized Manufacturers. International Journal of Physical Distribution and Logistics Management 32(9), 771-782 (2002)

29. Huxam, C.: Collaboration and Collaborative Advantage. Creating Collaborative Advantage. SAGE Publications Ltd., London (1996)

30. Ireland, R., Bruce, R.: CPFR: Only the Beginning of Collaboration. Supply Chain Management Review, 80 (September/October 2000)

31. IBM, IBM Product Lifecycle Management (PLM) (June 2001)

32. Jarillo, J.C.: On Strategic Networks. Strategic Management Journal 9(1), 31-41 (1988)

33. Jones, S., Wilikens, M., Morris, P., Masera, M.: Trust Requirements in E-Business. Communications of the ACM 43(2), 81-87 (2000)

34. Johnson, M.E., Whang, S.: E-Business and Supply Chain Management: An Overview and Framework. Production and Operations Management 11(4), 413-422 (2002)

35. Jordan Jr., J.A., Michael, F.J.: Next Generation Manufacturing: Methods and Techniques. John Wiley and Sons Inc., New York (2000)

36. Kai, W., Kai, R.: Trust Building Potential of Coordination Roles in Virtual Organizations. The Electronic Journal for Virtual Organizations and Networks (2007)

37. Kim, P.H., Dirks, K.T., Cooper, Y.D.: The Repair of Trust: A Dynamic Bilateral Perspective and Multilevel Conceptualization. Academy of Management Review 34(3), 401-422 (2009)

38. Kock, N., Nosek, J.: Expanding the Boundaries of E-Collaboration. IEEE Transactions on Professional Communication 48(1), 1-9 (2005)

39. Kwon, G.: Factors Affecting the Level of Trust and Commitment in Supply Chain Relationships. The Journal of Supply Chain Management (2004)

40. Kramer, R.M.: Trust and Distrust in Organizations: Emerging Perspectives, Enduring Questions. Annual Review of Psychology 50, 569-598 (1999)

41. Kim, P.H., Dirks, K.T., Cooper, Y.D.: The Repair of Trust: A Dynamic Bilateral Perspective and Multilevel Conceptualization. Academy of Management Review 34(3), 401-402 (2009) 
42. Kick, N., D'Arcy, J.: Resolving the e-collaboration Paradox: The Competing Influences of Media Naturalness and Compensatory Adaptation. Information Management and Consulting, Special Issue on Electronic Collaboration 17(4), 72-78 (2002)

43. Lane, C.: The Social Regulation of Inter-firm Relations in Britain and German: Market Rules, Legal Norms and Technical Standard. Cambridge Journal of Economics 21, 278289 (1997)

44. Lane, C., Bachmann, R.: The Social Constitution of Trust: Supplier Relation in Britain and Germany. Organizations Studies 17(3), 365-395 (1996)

45. Laubacher, R.J., Malone, T.W.: MIT Scenario Working Group. Two Scenarios for 21st Century Organizations Shifting Networks of Small Firms or all Encompassing 'Virtual Countries'?, Working Paper, 21CWP (1) (1997)

46. Lippert, S.K.: An Exploratory Study into the Relevance of Trust in the Context of Information Systems Technology. Doctoral Dissertation, The George Washington University, Washington, DC (2001)

47. Mayer, R.C., Davis, J., Schoorman, F.D.: AN Integrative Model of Organization Trust. Academy of Management Review 20(3), 709-734 (1995)

48. McLaren, T., Head, M., Yuan, Y.: Supply Chain Collaboration Alternatives: Understanding the Expected Costs and Benefits. Internet Research 12(4), 348-364 (2002)

49. Meyerson, D., Weick, K.E., Kramer, R.M.: Swift Trust and Temporary Groups. In: Kramer, R.M., Tyler, T.R. (eds.) Trust in Organizations, pp. 166-195. Sage, Thousand Oaks (1996)

50. Muckstadt, J.A., Murray, D.H., Rappold, J.A., Collins, D.E.: Guideline for Collaborative Supply Chain System Design and Operation. Information System Frontiers 3(4), 427-453 (2001)

51. McDonnell, M.: E-Collaboration: Transforming Your Supply Chain Into A Dynamic Trading Community. Supply Chain Practice 3(2), 80-89 (2001)

52. Ngai, E.W.T., Lai, K.H., Cheng, T.C.E.: Logistics Information Systems: The Hong Kong Experience. International Journal of Production Economics 113(1), 223-224 (2008)

53. Nooteboom, B., Berger, H., Noorderhaven, N.G.: Effects of Trust and Governance on Relational Risk. Academy of Management Review 40(2), 308-338 (1997)

54. Ofstad, H.: An Inquiry into the Freedom of Decision. Norwegian Universities Press, Oslo (1961)

55. Pramatari, K.: Collaborative Supply Chain Practices and Evolving Technological Approaches. An International Journal of Supply Chain Management 12(3), 210-220 (2007)

56. Ratnasingam, P.: Inter-Organizational Trust in EDI Adoption. The Case of Ford Motor Company and PBR Limited in Australia. Internet Research: Electronic Networking Applications and Policy 11(3), 261-268 (2001)

57. Rohde, J., Meyr, H., Wagner, M.: Die Supply Chain Planning Matrix. PPS Management 5(1), 10-15 (2000)

58. Sako, M.: Does Trust Improve Business Performance? In: lane, C., Bachmann, R. (eds.) Trust Within and Between Organization. Oxford University Press, Oxford (1998)

59. Shang, R., Chen, C.C., Liu, Y.: Internet EDI Adoption Factors: Power, Trust and Vision. In: Proceeding of International Conference on E-Commerce (ICEC 2005) (2005), http: / / portal.acm.org

60. Fawcett, S.E., Jones, S.L., Fawcett, A.L.: Supply Chain Trust: The Catalyst for Collaborative Innovation. Business Horizons 55, 163-178 (2012)

61. Van Goor, A.R., Ploos van Amstel, M.J., Ploos van Amstel, W.: Fysieke Distributie, Denken in Toegevoegde Waarden. Stenfert Kroes, Houten (1996) (in Dutch) 
62. Wehmeyer, K., Riemer, K.: Trust Building Potential of Coordination Roles in Virtual Organizations. The Electronic Journal for Virtual Organizations and Network 8 (2007)

63. Wicks, A.C., Berman, S.L.: The Effect of Context on Trust in Firm-Stakeholder Relationships: The Institutional Environment, Trust Creation and Firm Performance. Business Ethics Quarterly 14(1), 141-160 (2004)

64. Williams, L.R., Esper, T.L., Ozment, J.: The Electronic Supply Chain: Its Impact on the Current and Future Structure of Strategic Alliances, Partnerships and Logistics Leadership. International Journal of Physical Distribution and Logistics Management 32(8), 703-719

65. Zaheer, A., Harris, J.: Interorganizational Trust. In: Handbook of Strategic Alliances, pp. 169-197. Sage, Thousand Oaks (2006)

66. Zaheer, A., McEvily, B., Perrone, V.: Does Trust Matter? Exploring The Effects of Interorganizational and Inter-Personal Trust on Performance. Organization Science 9(2), 141-159 (1998)

67. Zineldin, M., Bredenlow, T.: Strategic Alliances: Synergies and Challenges. International Journal Physical Distribution and Logistics Management 33(5), 449-464 (2003) 